\title{
Brief communication: The global signature of post-1900 land ice wastage on vertical land motion
}

\author{
Riccardo E. M. Riva ${ }^{1}$, Thomas Frederikse ${ }^{1}$, Matt A. King ${ }^{2}$, Ben Marzeion ${ }^{3}$, and Michiel R. van den Broeke $\mathbf{e}^{4}$ \\ ${ }^{1}$ Department Geoscience and Remote Sensing, Delft University of Technology, Delft, 2618 CN, the Netherlands \\ ${ }^{2}$ Surveying and Spatial Sciences, School of Land and Food, University of Tasmania, Hobart, Tasmania, Australia \\ ${ }^{3}$ Institute of Geography, University of Bremen, Bremen, Germany \\ ${ }^{4}$ Institute for Marine and Atmospheric Research Utrecht, Utrecht University, Utrecht, the Netherlands \\ Correspondence to: Riccardo E. M. Riva (r.e.m.riva@tudelft.nl)
}

Received: 27 November 2016 - Discussion started: 15 December 2016

Revised: 26 April 2017 - Accepted: 2 May 2017 - Published: 6 June 2017

\begin{abstract}
Melting glaciers, ice caps and ice sheets have made an important contribution to sea-level rise through the last century. Self-attraction and loading effects driven by shrinking ice masses cause a spatially varying redistribution of ocean waters that affects reconstructions of past sea level from sparse observations. We model the solid-earth response to ice mass changes and find significant vertical deformation signals over large continental areas. We show how deformation rates have been strongly varying through the last century, which implies that they should be properly modelled before interpreting and extrapolating recent observations of vertical land motion and sea-level change.
\end{abstract}

\section{Introduction}

The amount of ice stored on land has strongly declined during the 20th century, and melt rates have shown a significant acceleration over the last 2 decades. Land ice wastage is well known to be one of the main drivers of global mean sea-level rise, as widely discussed in the literature and reflected in the last assessment report of the IPCC (Church et al., 2013). They show that the century-long trend in ice mass loss is mainly due to melting mountain glaciers (Fig. 1, right panel), while the recent acceleration is mostly driven by increased mass loss from the Greenland and the Antarctic ice sheets.

A less obvious effect of melting land ice is the response of the solid earth to mass redistribution on its surface, which, in the first approximation, results in land uplift where the load reduces (e.g., close to the meltwater sources) and land subsidence where the load increases (e.g., under the rising oceans). This effect is nowadays well known within the cryospheric and sea-level communities (Watson et al., 2015). However, what those communities often do not realise is that the solid-earth response is a truly global effect: a localised mass change does cause a large deformation signal in its proximity but also causes a change of the position of every other point on the Earth's surface. The theory of the Earth's viscoelastic response to changing surface loads forms the basis of the "sea-level equation" (Farrell and Clark, 1976), which allows sea-level fingerprints of continental mass change to be computed.

In this brief communication, we provide the first dedicated analysis of century-long global vertical land motion driven by land ice wastage and based on realistic ice sources. By means of established techniques to compute the solidearth elastic response to surface load changes and the most recent datasets of glacier and ice sheet mass change, we show that land ice loss currently leads to vertical deformation rates of several tenths of a millimetre per year at midlatitudes, especially over the Northern Hemisphere, where most sources are located. In combination with the improved accuracy of space geodetic techniques (e.g., global satellite navigation systems), this means that the effect of ice melt is non-negligible over a large part of the continents. In particular, we show how the recent acceleration in melt rates affects estimates of secular vertical land motion and therewith has an impact on various geodetic applications, including estimates of long-term sea-level rise at tide gauges. While elas- 

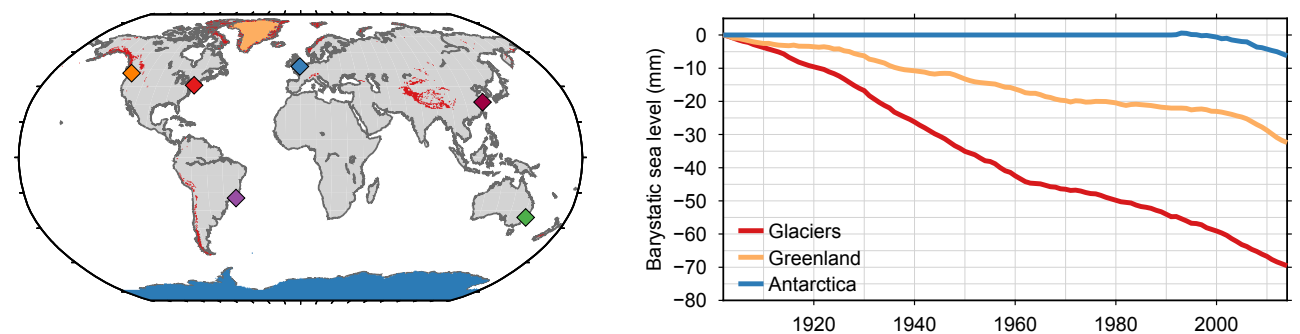

Figure 1. Left: land ice regions considered in this study (red, glaciers; orange, Greenland; blue, Antarctica), with coloured diamonds representing the coastal cities of Fig. 3. Right: global mean sea-level contribution of ice wastage between years 1902 and 2014.

tic deformation of the Earth has been widely considered due to especially atmospheric loading changes, the effects of ice loading changes have been largely ignored, due to the difficulty of an accurate quantification of the melting histories (Santamaria-Gomez and Memin, 2015).

\section{Datasets and methods}

As in Frederikse et al. (2016), we consider yearly mass losses from glaciers and ice caps and the Greenland and Antarctic ice sheets. For glacier mass loss, the recent estimate of Marzeion et al. (2015) is used. For the Greenland ice sheet during the period 1902-1992 we use data from Kjeldsen et al. (2015). Between years 1993 and 2014, we use an inputoutput approach for both Greenland and Antarctica: input is based on the modelled RACMO2.3 surface mass balance (SMB; Van den Broeke et al., 2016); Greenland ice discharge is also based on van den Broeke et al. (2016). For Antarctica, the ice discharge is parametrised as a constant acceleration of $2.0 \mathrm{Gt} \mathrm{yr}^{-2}$, starting from equilibrium between 1979 and 1992, which gives a good fit with IMBIE estimates (Shepherd et al., 2012). Figure 1 shows the location of the glaciers and ice sheets on which our mass balance estimates are based, together with the equivalent sea-level change of the individual iced regions. The glacier mass loss is regionalised following the regions described in Pfeffer et al. (2014). For both ice sheets, the spatial distribution of the mass change is based on linear trends obtained from GRACE JPL mascon solutions (Watkins et al., 2015), scaled to match the estimated total mass loss (Frederikse et al., 2016). Note that this approach will bias the resulting fingerprints towards post-2002 values (e.g., the signal over the Antarctic Peninsula contains the signature of the glacier acceleration following the 2002 Larsen B Ice Shelf breakup), but with a limited effect on the far-field signal.

We determine the solid-earth elastic response by solving the sea-level equation (Farrell and Clark, 1976) for each load in each year and add them together to obtain the total response, where superimposition is allowed by the linearity of the sea-level equation under the assumption of fixed coastlines. We follow a pseudo-spectral approach (Tamisiea et al., 2010) in the centre of mass of the Earth system (CM), solved up to spherical harmonic degree 360 for a compressible and spherically layered Earth, including the effect of induced changes in the Earth's rotation. We then estimate a linear trend through the resulting vertical land motion time series, over each time-window under study, by means of ordinary least squares. We have chosen to solve the sea-level equation in the CM frame, since this is the natural reference for sea-level observations (the sea surface at rest follows the geoid, which is centred at the CM).

\section{Results}

Global maps of vertical deformation rates are shown in Fig. 2 for different time spans. In all panels, the largest values are reached at the location of the melt sources, while the far-field negative deformation is shaped by the change in the position of the Earth's rotation axis.

The near-field deformation rates are dominated by the direct effect of the individual melt sources. The maximum uplift rates are reached over Greenland and range from about $4 \mathrm{~mm} \mathrm{yr}^{-1}$ (panel a) to $11 \mathrm{~mm} \mathrm{yr}^{-1}$ (panel d), though the exact values are dependent on the model resolution $\left(0.5^{\circ}\right)$ and on the accuracy of the melt distribution and of the regional mass loss values.

In the far field, here loosely defined as regions located several hundred kilometres away from any region of ice mass loss and characterized by small gradients in vertical deformation rates, maximum uplift rates have increased from less than $0.6 \mathrm{~mm} \mathrm{yr}^{-1}$ over the last century to about $1.0 \mathrm{~mm} \mathrm{yr}^{-1}$ during the last decade. Larger rates are combined with a southward shift of the $0.4 \mathrm{~mm} \mathrm{yr}^{-1}$ contour, which has moved over North America from south of Hudson Bay to about Washington, D.C., and over Europe from Denmark to northern Italy. During the last decade, most of Australia has been subsiding because of contemporary ice mass change at rates larger than $0.4 \mathrm{~mm} \mathrm{yr}^{-1}$, consistent with GPS estimates. Interestingly, the far-field deformation pattern in central Asia is not very different through the century, being dominated by the relatively constant effect of glacier mass loss on and around the Tibetan Plateau. The increased deformation rates during the satellite era are highlighted in the bottom panels of Fig. 2, showing the difference between the 

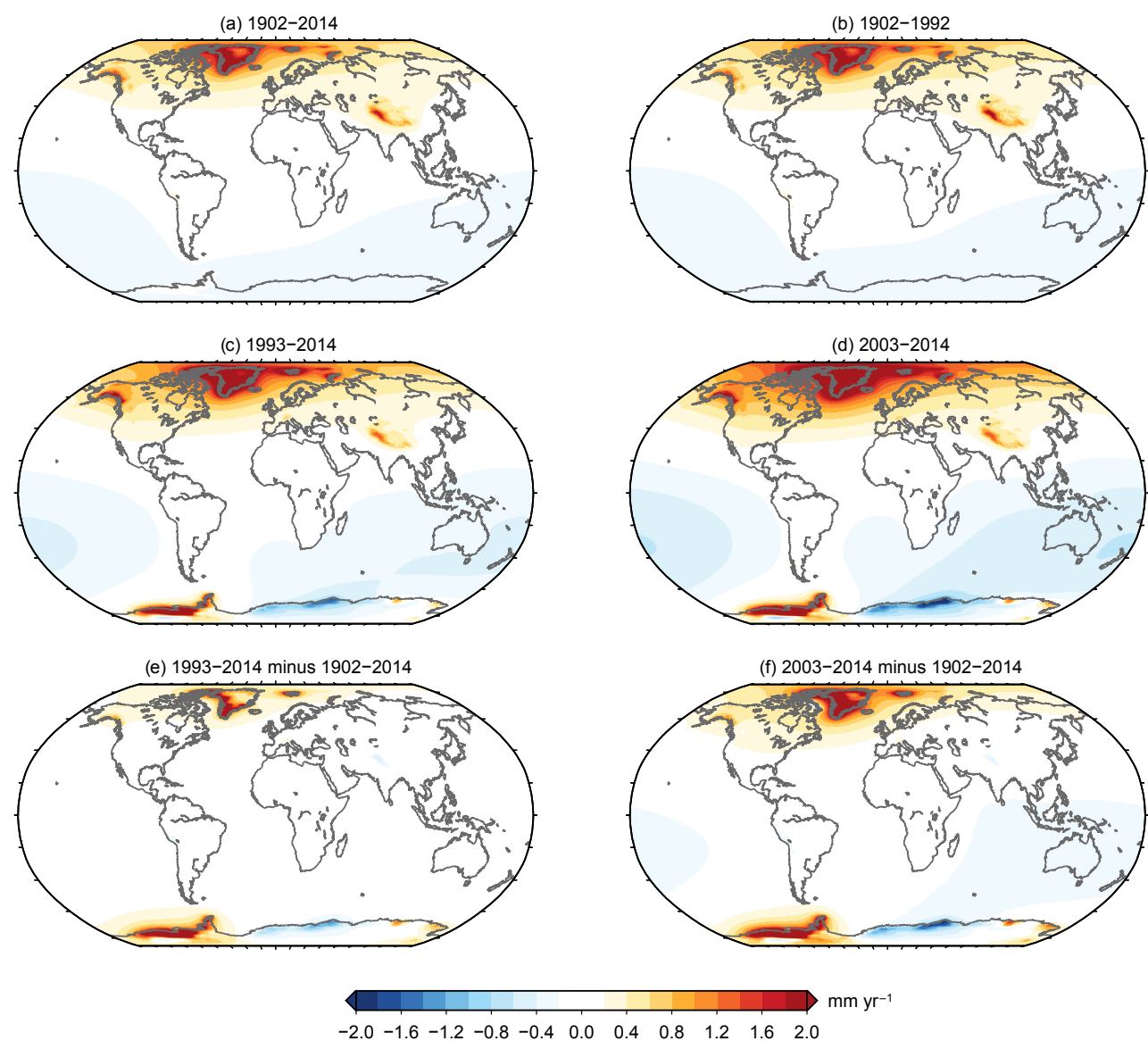

Figure 2. Maps of average vertical deformation rates over different time spans. (a) Full time span covered by this study; (b) pre-satellite era; (c) the GPS era; (e) the GRACE era; (e) panel (c) minus panel (a); (f) panel (d) minus panel (a).

last decades and the long-term average: as already pointed out about Fig. 1, most of the differences originate from the two ice sheets.

In order to better show the temporal evolution of vertical land motion through the last century, in Fig. 3 we display time series of the signal and of its time derivative for six major cities worldwide. Note that deformation rates were computed after using a 15 -year moving average. We have specifically chosen coastal cities not only because they are representative of the far-field deformation over large portions of the continents, due to the smoothness of the signal, but also because vertical land motion has a direct effect on sea-level change and on tide gauge measurements of that change.

In the course of the 113 years covered by this study, due to continental ice mass loss alone, cities in the Northern Hemisphere have accumulated several centimetres of uplift $(2.8 \mathrm{~cm}$ for New York, $3.9 \mathrm{~cm}$ for London, $5.0 \mathrm{~cm}$ for Seattle), while cities in the Southern Hemisphere have subsided (Rio by $1.0 \mathrm{~cm}$, Sydney by $3.4 \mathrm{~cm}$ ). At lower latitudes the signal is smaller; e.g. Shanghai has been uplifted by $1.0 \mathrm{~cm}$. These changes are in addition to vertical land motion due to other processes.
The vertical motion has not been constant in time, following temporal variations in ice mass loss rates. In particular, rates were lower at the beginning of the last century and in the 1970s, while a clear acceleration can be seen during the last 20 years, when the ice sheets' contribution has increased (bottom panels of Fig. 2). Interestingly, the recent high rates are not exceptional at all locations, depending on the relative distance from specific glaciers and the two ice sheets. For example, in Seattle rates above $0.6 \mathrm{~mm} \mathrm{yr}^{-1}$ were already reached in the 1930s, while in London the recent rates of about $0.5 \mathrm{~mm} \mathrm{yr}^{-1}$ are lower than those experienced in the 1930s. The increased contribution of the ice sheets can also lead to a reduction in the local deformation rates; this is the case for Shanghai, which is currently experiencing very little vertical motion associated with ice melt, due to its location on the transition line between uplift driven by northern sources and subsidence enhanced by the small recent mass gain in East Antarctica. 

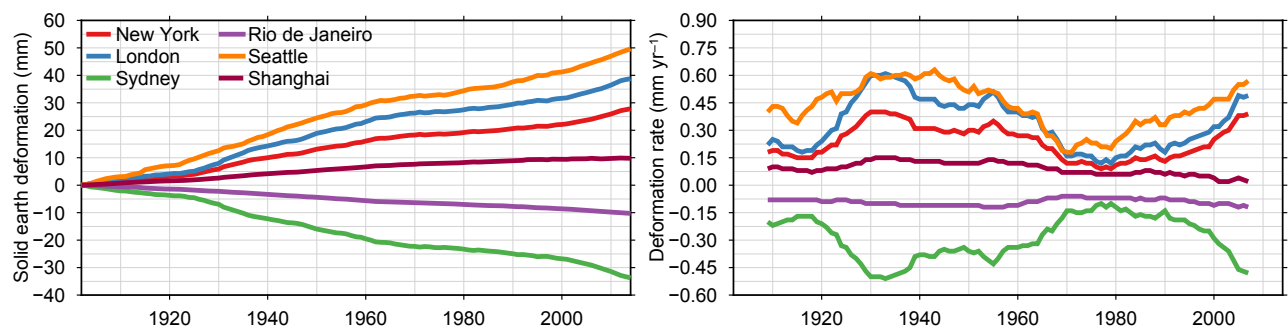

Figure 3. Time series of vertical deformation (left panel) and 15-year average rates (right panel) at selected coastal cities due to global ice mass changes. The locations of the cities are indicated by diamonds in Fig. 1a, following the same colour coding.

\section{Discussion}

Long-term vertical land motion in the near-field is dominated by the effect of ice loss, which allows geodetic observations to be used to quantify ice mass change (e.g., Bevis et al., 2012) or to separate the effect of present-day mass loss from the signature of glacial isostatic adjustment (GIA) (e.g., Kahn et al., 2016).

In the far field, several competing processes can lead to interannual vertical deformation rates at the millimetre-peryear level. For this reason, geodetic observations are usually corrected for the effect of a number of loading processes related to water mass redistribution, such as changes in atmospheric pressure, land hydrology and ocean mass (Santamaria-Gomez and Memin, 2015). This approach is problematic when studying the effect of climate change, since current models of the water cycle are not accurate in terms of interannual and secular variations, which are orders of magnitude smaller than those driven by the seasonal cycle.

The remaining signal is usually attributed to geodynamic processes (e.g., GIA, earthquakes, volcanoes, landslides) or to local effects, either of natural (e.g., ground compaction, sediment transport) or of anthropogenic origin (e.g., groundwater and hydrocarbons extraction, dam building). Of all those processes, only GIA (e.g., Peltier et al., 2015) and coseismic deformation (Melini et al., 2004) can currently be modelled globally, albeit with large uncertainties. While Earth rotational effects are modelled in geodetic data analysis, those are entirely limited to quasi-annual variations (King and Watson, 2014), meaning that the decadal and secular signals contributing to vertical land motion as identified in this study are not considered.

The general approach in sea-level studies until the early 2000s was to neglect any non-GIA signal, meaning that sealevel estimates based on tide gauges were potentially biased by several tenths of a millimetre per year, as recently discussed by Hamlington et al. (2016). More recently, estimates of vertical land motion have been obtained by the combination of observations from satellite altimetry and tide gauges (Nerem and Mitchum, 2002) or by direct observations by means of GPS (e.g., Santamaría-Gómez et al., 2014; Woppelmann and Marcos, 2016). However, the majority of those approaches are limited by the fact that space geodetic observations are only available beginning in the 1990s, when the effect of ice wastage as considerably larger than during the rest of the 20th century (Fig. 2c vs. Fig. 2b). The assumption of constant rates throughout the century means that significant errors in sea-level reconstructions based on tide gauge records will still be present, even after correcting for vertical land motion as observed by GPS, especially if the observations were collected during the last decade. For example, the dominantly positive rates in the Northern Hemisphere could explain up to a few tenths of a millimetre per year of the hemispheric difference in sea-level rise found by Wöppelmann et al. (2014).

Global vertical land motion is also changing the shape of the ocean basins (Fig. 2), which causes a bias in sea-level change estimates based on satellite altimetry. However, during 1993-2014, this effect is less than $-0.11 \mathrm{~mm} \mathrm{yr}^{-1}$ over the global ocean $\left(-0.07 \mathrm{~mm} \mathrm{yr}^{-1}\right.$ between $\pm 66^{\circ}$ latitude), largely within the uncertainty of space-based estimates of global mean sea-level change. Additionally, the vertical land motion discussed in the GPS context could induce an additional bias in altimetry estimates, due to the use of tide gauges to determine altimeter drift (Watson et al., 2015).

It is worth noticing that we have modelled the Earth's elastic deformation but neglected the viscoelastic response of the mantle (Farrell and Clark, 1976; Peltier et al., 2015); however, the far-field signature of relaxation is controlled by viscoelastic relaxation mostly taking place deep in the mantle, which is expected to provide a significant response at timescales much longer than those covered by this study.

Considering the recent improvement in mass loss reconstructions of glaciers and ice caps (Marzeion et al., 2015) and ice sheet (Shepherd et al., 2012), even though the 20thcentury contribution of Antarctica is still poorly understood, we advocate direct modelling of the effect of time-varying ice wastage as a way to improve the accuracy of sea-level change estimates (Frederikse et al., 2016).

\section{Conclusions}

We have shown how land ice wastage through the last century has caused vertical land motion in the order of several 
tenths of a millimetre per year over large parts of the continents. Deformation rates are highly non-linear and locationdependent, with larger values between 1930 and 1950, minima around 1970 and a clear acceleration during the last 2 decades.

This effect is particularly important in the context of sealevel studies, since several of the longest tide gauge records are at mid-latitudes in the Northern Hemisphere, where the effect of mass loss of Arctic glaciers and the Greenland ice sheet is large, as also discussed by Thompson et al. (2016).

In particular, due to the recent acceleration in land ice mass loss, which represents one of the largest drivers of regional vertical land motion, the estimation of secular rates from GPS observations should account for the effect of glacial mass change.

Data availability. The data used to generate Figs. 2 and 3, in the form of NetCDF files containing gridded values of annual vertical deformation, are freely available through the 4TU.Centre for Research Data at https://doi.org/10.4121/uuid:fb667e7a-52f34876-8cab-ae7a2ddaf0db (Riva et al., 2017). For the data used to generate Fig. 1, we refer to the original papers.

Author contributions. Riccardo E. M. Riva and Thomas Frederikse designed the study. Thomas Frederikse performed the computations and produced the figures. Riccardo E. M. Riva wrote the paper. Matt A. King contributed to the analysis of the results. Ben Marzeion provided glacier mass balance data. Michiel van den Broeke provided ice sheet SMB data. All authors commented on the manuscript.

Competing interests. The authors declare that they have no conflict of interest.

Acknowledgements. Riccardo E. M. Riva and Thomas Frederikse acknowledge funding from The Netherlands Organisation for Scientific Research (NWO) through VIDI grant no 864.12.012. Matt A. King is a recipient of an Australian Research Council Future Fellowship (project number FT110100207) and supported by the Australian Research Council Special Research Initiative for Antarctic Gateway Partnership (Project ID SR140300001). Michiel van den Broeke acknowledges funding from the Netherlands Polar Programme and the Netherlands Earth System Science Centre (NESSC). We are grateful to Kristian Kjeldsen and Kurt Kjær for sharing Greenland mass loss data.

Edited by: E. Berthier

Reviewed by: A. Santamaría-Gómez and one anonymous referee

\section{References}

Bevis, M., Wahr, J., Khan, S. A., Madsen, F. B., Brown, A., Willis, M., Kendrick, E., Knudsen, P., Box, J. E., van Dam, T., and Caccamise, D. J.: Bedrock displacements in Greenland manifest ice mass variations, climate cycles and climate change, Proceedings of the National Academy of Sciences, 109, 11944-11948, 2012.

Church, J. A., Clark, P. U., Cazenave, A., Gregory, J. M., Jevrejeva, S., Levermann, A., Merrifield, M. A., Milne, G. A., Nerem, R. S., Nunn, P. D., Payne, A. J., Pfeffer, W. T., Stammer, D., and Unnikrishnan, A. S.: Sea Level Change. In: Climate Change 2013: The Physical Science Basis. Contribution of Working Group I to the Fifth Assessment Report of the Intergovernmental Panel on Climate Change, edited by: Stocker, T. F., Qin, D., Plattner, G.K., Tignor, M., Allen, S. K., Boschung, J., Nauels, A., Xia, Y., Bex, V., and Midgley, P. M., Cambridge University Press, Cambridge, United Kingdom and New York, NY, USA, 2013.

Farrell, W. E. and Clark, J. A.: On postglacial sea level, Geophys. J. Int., 46, 647-667, 1976.

Frederikse, T., Riva, R., Slobbe, C., Broerse, T., and Verlaan, M.: Estimating decadal variability in sea level from tide gauge records: An application to the North Sea, J. Geophys. Res.-Oceans, 121, 1529-1545, https://doi.org/10.1002/2015JC011174, 2016

Hamlington, B. D., Thompson, P., Hammond, W. C., Blewitt, G., and Ray, R. D.: Assessing the impact of vertical land motion on twentieth century global mean sea level estimates, J. Geophys. Res.-Oceans, 121, 4980-4993, 2016.

Khan, S. A., Sasgen, I., Bevis, M., van Dam, T., Bamber, J. L., Wahr, J., Willis, M., Kjær, K. H., Wouters, B., Helm, V., and Csatho, B.: Geodetic measurements reveal similarities between post-Last Glacial Maximum and present-day mass loss from the Greenland ice sheet, Sci. Adv., 2, e1600931, https://doi.org/10.1126/sciadv.1600931, 2016.

King, M. A. and Watson, C. S.: Geodetic vertical velocities affected by recent rapid changes in polar motion, Geophys. J. Int., 199, 1161-1165, 2014.

Kjeldsen, K. K., Korsgaard, N. J., Bjørk, A. A., Khan, S. A., Funder, S., Larsen, N. K., Bamber, J. L., Colgan, W., van den Broeke, M., Siggaard-Andersen, M. L., and Nuth, C.: Spatial and temporal distribution of mass loss from the Greenland Ice Sheet since AD 1900, Nature, 528, 396-400, 2015.

Marzeion, B., Leclercq, P. W., Cogley, J. G., and Jarosch, A. H.: Brief Communication: Global reconstructions of glacier mass change during the 20th century are consistent, The Cryosphere, 9, 2399-2404, https://doi.org/10.5194/tc-9-2399-2015, 2015.

Melini, D., Piersanti, A., Spada, G., Soldati, G., Casarotti, E., and Boschi, E.: Earthquakes and relative sealevel changes, Geophys Res. Lett., 31, L09601, https://doi.org/10.1029/2003GL019347, 2004.

Nerem, R. S. and Mitchum, G. T.: Estimates of vertical crustal motion derived from differences of TOPEX/POSEIDON and tide gauge sea level measurements, Geophys. Res. Lett., 29, 1934, https://doi.org/10.1029/2002GL015037, 2002.

Peltier, W. R., Argus, D. F., and Drummond, R.: Space geodesy constrains ice age terminal deglaciation: The global ICE-6G_C (VM5a) model, J. Geophys. Res.-Solid Earth, 120, 450-487, 2015.

Pfeffer, W. T., Arendt, A. A., Bliss, A., Bolch, T., Cogley, J. G., Gardner, A. S., Hagen, J. O., Hock, R., Kaser, G., Kienholz, C., 
and Miles, E. S.: The Randolph Glacier Inventory: a globally complete inventory of glaciers, J. Glaciol., 60, 537-552, 2014.

Riva, R. E. M., Frederikse, T., King, M. A., Marzeion, B., and van den Broeke, M.: Data Supplement to: Brief Communication: The global signature of post-1900 land ice wastage on vertical land motion, available at: https://doi.org/10.4121/uuid:fb667e7a52f3-4876-8cab-ae7a2ddaf0db, 2017.

Santamaría-Gómez, A., Gravelle, M., and Wöppelmann, G.: Long-term vertical land motion from double-differenced tide gauge and satellite altimetry data, J. Geod., 88, 207-222, https://doi.org/10.1007/s00190-013-0677-5, 2014.

Santamaría-Gómez, A. and Mémin, A.: Geodetic secular velocity errors due to interannual surface loading deformation, Geophys. J. Int., 202, 763-767, 2015.

Shepherd, A., Ivins, E. R., Geruo, A., Barletta, V. R., Bentley, M. J., Bettadpur, S., Briggs, K. H., Bromwich, D. H., Forsberg, R., Galin, N., and Horwath, M.: A reconciled estimate of ice-sheet mass balance, Science, 338, 1183-1189, 2012.

Tamisiea, M. E., Hill, E. M., Ponte, R. M., Davis, J. L., Velicogna, I., and Vinogradova, N. T.: Impact of self-attraction and loading on the annual cycle in sea level, J. Geophys. Res., 115, C07004, https://doi.org/10.1029/2009JC005687, 2010.

Thompson, P. R., Hamlington, B. D., Landerer, F. W., and Adhikari, S.: Are long tide gauge records in the wrong place to measure global mean sea level rise?, Geophys. Res. Lett., 43, $10403-$ 10411, https://doi.org/10.1002/2016GL070552, 2016. van den Broeke, M. R., Enderlin, E. M., Howat, I. M., Kuipers Munneke, P., Noël, B. P. Y., van de Berg, W. J., van Meijgaard, E., and Wouters, B.: On the recent contribution of the Greenland ice sheet to sea level change, The Cryosphere, 10, 1933-1946, https://doi.org/10.5194/tc-10-1933-2016, 2016.

Watkins, M. M., Wiese, D. N., Yuan, D.-N., Boening, C., and Landerer, F. W.: Improved methods for observing Earth's time variable mass distribution with GRACE using spherical cap mascons, J. Geophys. Res.-Solid Earth, 120, 2648-2671, https://doi.org/10.1002/2014JB011547, 2015.

Watson, C. S., White, N. J., Church, J. A., King, M. A., Burgette, R. J., and Legresy, B.: Unabated global mean sea-level rise over the satellite altimeter era, Nature Climate Change, 5, 565-568, 2015.

Wöppelmann, G. and Marcos, M.: Vertical land motion as a key to understanding sea level change and variability, Rev. Geophys., 54, 64-92, https://doi.org/10.1002/2015RG000502, 2016.

Wöppelmann, G., Marcos, M., Santamaría-Gómez, A., MartínMíguez, B., Bouin, M.-N., and Gravelle, M.: Evidence for a differential sea level rise between hemispheres over the twentieth century, Geophys. Res. Lett., 41, 1639-1643, https://doi.org/10.1002/2013GL059039, 2014. 